\title{
FATORES DE EMISSÃO DE COMPOSTOS CARBONÍLICOS MEDIDOS EM UM TÚNEL DO RIO DE JANEIRO, BRASIL, EM CONDIÇÕES REAIS DE DIRIGIBILIDADE
}

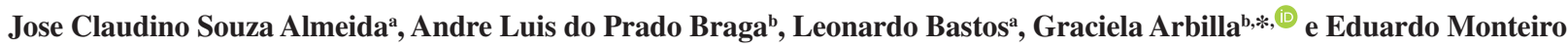 \\ Martins $^{\text {a }}$ \\ aDepartamento de Engenharia Sanitária e do Meio Ambiente, Faculdade de Engenharia, Universidade do Estado do Rio de Janeiro, \\ Rio de Janeiro, 20550-900 Rio de Janeiro - RJ, Brasil \\ 'Instituto de Química, Universidade Federal do Rio de Janeiro, 21941-909 Rio de Janeiro - RJ, Brasil
}

Recebido em 17/12/2019; aceito em 15/01/2020; publicado na web em 31/03/2020

\begin{abstract}
REAL-WORLD EMISSION FACTORS OF CARBONYL COMPOUNDS MEASURED IN A RIO DE JANEIRO TUNNEL, BRAZIL. Real-world vehicle emissions of carbonyls compounds (CC) were determined at the Rebouças Tunnel, Rio de Janeiro (Brazil). The tunnel is a two-bore tunnel with three lanes in each direction and has a length of $2840 \mathrm{~m}$, divided in two sections. On average, approximately 5,000 vehicles (95\% light duty) were passing the tunnel per hour. Sixteen samples were simultaneously collected 500 and $1500 \mathrm{~m}$ inside from the entrance. The main CC were formaldehyde, acetaldehyde, acetone, propionaldehyde and benzaldehyde. A total of 16 samples were collected in each point in 8 different days. In 5 days, $\mathrm{CO}$ and $\mathrm{CO}_{2}$ were also monitored during the sampling period. Emission factors were calculated. Using the Pierson method, emission factors were $7.5 \pm 2.6$ and $13.8 \pm 5.7 \mathrm{mg} \mathrm{km}^{-1}$ for formaldehyde and acetaldehyde, respectively. Using the fuel consumption method, values were $6.3 \pm 2.1$ and $11.8 \pm 3.9 \mathrm{mg} \mathrm{km}^{-1}$ for the same compounds. The differences between both methods were lower than $20 \%$ and may be considered acceptable considering all the approximations in the calculations. Ozone forming potentials (OFP) were also estimated as $90.4 \pm 37.3$ and $70.7 \pm 24.6 \mathrm{mg} \mathrm{km}^{-1}$ for formaldehyde and acetaldehyde, respectively.
\end{abstract}

Keywords: emission factor; tunnel; carbonyl compounds.

\section{INTRODUÇÃO}

A qualidade do ar de uma região é resultado de complexas interações, envolvendo a emissão de poluentes atmosféricos por fontes fixas e móveis, locais e remotas, naturais e antropogênicas que, em conjunto com as condições meteorológicas e das características do relevo em estudo, determinam a concentração dos compostos presentes na atmosfera. As emissões veiculares são consideradas as principais fontes para a poluição atmosférica nas grandes metrópoles do mundo. ${ }^{1,2}$

Nos Estados Unidos, dados recentes publicados pela Agência de Proteção Ambiental (EPA) indicam que 52\% das emissões de $\mathrm{CO}$ e $57 \%$ de $\mathrm{NO}_{\mathrm{x}}$ (onde $\mathrm{NO}_{\mathrm{x}}$ indica a soma de $\mathrm{NO}+\mathrm{NO}_{2}$ ) são originadas no setor de transporte. ${ }^{3}$ No caso da Europa, um estudo publicado pela Agencia Europeia do Ambiente, indicou que $39 \%$ do $\mathrm{NO}_{\mathrm{x}}$ e $20 \%$ do CO são oriundos do setor de transporte. ${ }^{4}$

No Brasil, segundo o último inventário da CETESB,${ }^{5}$ relativo ao ano de 2018 para o Estado de São Paulo, 97,86\% das emissões de CO; 76,27\% das emissões de hidrocarbonetos e 66,62\% das emissões primárias de óxidos de nitrogênio são contribuições diretas de fontes móveis. Ainda, de acordo com o mesmo inventário, apenas os aportes de $\mathrm{SO}_{2}$ e de material particulado para a atmosfera têm contribuições mais importantes a partir das fontes fixas, respectivamente, $71,4 \%$ e $83,0 \%$.

O aprofundamento nos estudos relativos às fontes de emissão veicular se torna de grande relevância e o seu entendimento passa por diversas metodologias, cada uma com suas especificidades. Dessa forma, podemos destacar a contribuição dos estudos feitos em túneis. $\mathrm{O}$ interior de um túnel funciona como um simulador de emissões veiculares, livre da influência de outras fontes de emissão e até das condições meteorológicas, assim, as concentrações medidas para os

*e-mail: gracielaiq@gmail.com poluentes correspondem majoritariamente às emissões dos veículos circulantes, nas condições normais de utilização para um dado centro urbano. Neste contexto, podemos destacar alguns estudos realizados em túneis. Por exemplo, Cui et al. avaliaram os efeitos práticos de uma série de medidas de controle das emissões veiculares propostas pelo governo de Hong Kong. ${ }^{6} \mathrm{O}$ estudo contemplou os resultados de duas campanhas realizadas no mesmo túnel, uma em 2003 e outra em 2015. As taxas de emissão foram calculadas pela metodologia de Pierson e os valores médios encontrados para os compostos orgânicos voláteis decresceram em aproximadamente $44,7 \%$, se comparadas as duas campanhas. ${ }^{6}$ Especificamente, a taxa de emissão do eteno reduziu $67,4 \%$.

No Brasil, também foram realizados estudos para determinação da concentração de poluentes no interior de túneis, incluindo algumas medições para a obtenção de fatores de emissão. Por exemplo, com o objetivo de contribuir para a melhoria do inventário de emissões veiculares para a região metropolitana de São Paulo, Martins et al. ${ }^{7}$ fizeram campanhas de monitoramento, em 2004, em dois túneis, o Jânio Quadros, com perfil de frota leve, e o Maria Maluf, com perfil misto. As coletas foram realizadas em dois pontos, uma no interior e outra na entrada dos túneis. Foram monitorados $\mathrm{CO}, \mathrm{NO}_{\mathrm{x}}$, hidrocarbonetos e compostos carbonílicos. No túnel Jânio Quadros foram calculados fatores de emissão médios de 14,6 $\pm 2,3 \mathrm{~g} \mathrm{~km}^{-1}$ para $\mathrm{CO}$ e de 1,6 $\pm 0,3 \mathrm{~g} \mathrm{~km}^{-1}$ para $\mathrm{NO}_{\mathrm{x}}$ e, no túnel Maria Maluf, valores de 20,6 $\pm 4,7 \mathrm{~g} \mathrm{~km}^{-1}$ e 22,3 \pm 9,8 $\mathrm{g} \mathrm{km}^{-1}$. Para os compostos orgânicos voláteis (COVs) no túnel Maria Maluf, o valor médio foi de $1,4 \pm 1,3 \mathrm{~g} \mathrm{~km}^{-1}$. Segundo os autores, as elevadas emissões de $\mathrm{NO}_{\mathrm{x}}$ no túnel Maria Maluf foram atribuídas aos veículos movidos a diesel. ${ }^{7}$

Também no ano de 2004, Sánchez-Ccoyllo et al. avaliaram as emissões de material particulado (partículas grossas, finas, material inalável e black carbon) nos mesmos túneis, e concluíram que, de um modo geral, as emissões de material particulado em São Paulo são maiores que em outras cidades do mundo. ${ }^{8}$ 
Posteriormente foram publicados novos resultados obtidos em ambos os túneis em 2011, para emissões de $\mathrm{CO}, \mathrm{NO}_{\mathrm{x}}, \mathrm{CO}_{2}$ e material particulado. ${ }^{9}$ Os autores encontraram uma importante redução nos valores dos fatores de emissão, se comparados com os determinados no estudo de 2004 (fatores de 2,2 e 3,2 para CO e NO${ }_{x}$ respectivamente). Redução essa atribuída às melhoras tecnológicas apresentadas pela frota circulante, como por exemplo, os conversores catalíticos de três vias.

Em outro estudo, publicado em 2015, Nogueira et al. monitoraram compostos carbonílicos em dois túneis localizados na região metropolitana de São Paulo, o Jânio Quadros, mesmo túnel do estudo anterior, ${ }^{10}$ onde circula uma frota de característica leve e o túnel do Rodoanel, característico de frota mista. Da mesma forma que foi realizado no estudo anterior, os autores mediram em dois pontos, um no interior e outro na parte externa aos túneis. Foram calculados fatores de emissão para formaldeído de 5,7 $\pm 1,7$ e $28 \pm 8 \mathrm{mg} \mathrm{km}^{-1}$, respectivamente para veículos leves e pesados e $7,4 \pm 2,7$ e $20 \pm 16 \mathrm{mg} \mathrm{km}^{-1}$ de acetaldeído para veículos leves e pesados, também respectivamente.

Para a cidade do Rio de Janeiro, apesar de ser a segunda maior cidade do Brasil e com a segunda maior frota veicular, ${ }^{11}$ não existem, segundo nosso conhecimento, estudos calculando os fatores de emissão. Resultados obtidos em 2005 no túnel Rebouças, para compostos aromáticos, são os mais recentes publicados para túneis no Rio de Janeiro. Contudo, nesse trabalho foram informadas apenas as concentrações de alguns compostos, não sendo possível a partir desses resultados, calcular os fatores de emissão. ${ }^{12}$

Levando em consideração esse fator, o principal objetivo deste trabalho foi cobrir, mesmo que parcialmente, essa lacuna de informações relativas às estimavas do fator de emissão para frota que circula na cidade do Rio de Janeiro. Para isso, foram determinados os fatores de emissão para compostos carbonílicos, usando as metodologias de Pierson e de consumo de combustível, no túnel Rebouças onde os veículos leves são predominantes.

\section{PARTE EXPERIMENTAL}

\section{Local de amostragem}

Inaugurado em 16 de outubro de 1967, o túnel Rebouças, com seus $2840 \mathrm{~m}$ de comprimento, divididos em dois trechos, um de 2040 e outro de $800 \mathrm{~m}$, ainda é considerado a principal artéria de ligação entre as zonas sul e norte da Cidade do Rio de Janeiro. O túnel foi construído em duas galerias, L1 e L2, sendo a L1 no sentido da zona norte e L2 no sentido zona sul da cidade do Rio de Janeiro. A seção transversal de cada galeria é de aproximadamente $81 \mathrm{~m}^{2}$. Projetado inicialmente para duas faixas de rolamento e uma de acostamento, atualmente o túnel opera com três faixas e sem acostamento. A saída do trecho de $2040 \mathrm{~m}$ está $40 \mathrm{~m}$ acima da cota da entrada no bairro do Humaitá, dessa forma, e no sentido zona norte (galeria L1) a frota precisa acelerar para vencer uma inclinação de aproximadamente $2 \% .{ }^{12} \mathrm{~A}$ ventilação forçada é composta de 90 ventiladores, ligados de forma aleatória e sem horário fixo. Com um volume diário estimado em 190 mil veículos, uma média de aproximadamente 5000 por hora, o Rebouças apresenta um perfil característico com dois picos diários no fluxo, um pela manhã e outro no fim da tarde. Na Figura 1 são apresentados valores característicos de fluxo veicular no túnel Rebouças para um dia útil.

A composição da frota circulante também pode ser considerada característica. Conforme dados da administração do túnel Rebouças, os veículos leves representam $94 \%$ de toda a frota circulante, a fatia dos veículos pesados só alcança $1 \%$ do total, sendo restrita a ônibus e aos poucos caminhões autorizados, como, por exemplo, de limpeza
Perfil Horário Tipico - Túnel Rebouças

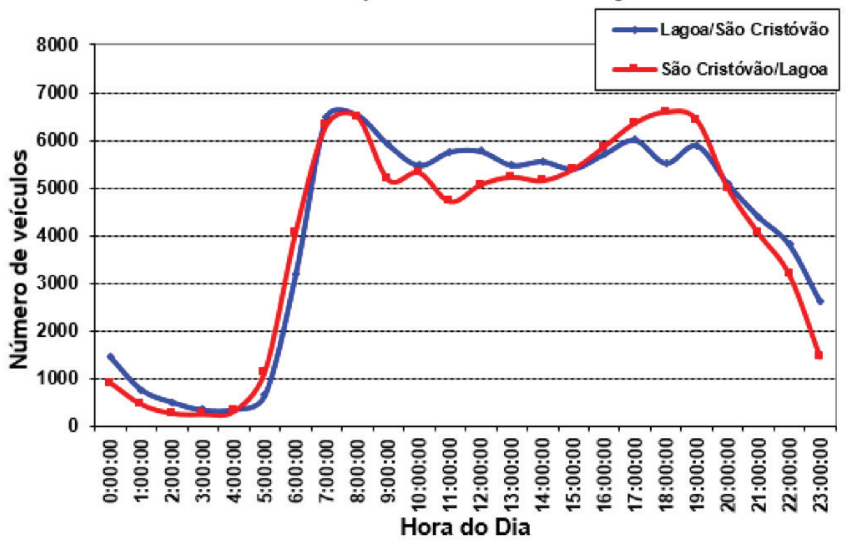

Figura 1. Valores típicos de fluxo veicular no túnel Rebouças para um dia útil. Fonte: Prefeitura da Cidade do Rio de Janeiro

urbana e bombeiros. As motos, com 4\%, e os denominados veículos médios (1\%), as vans, por exemplo, completam a estatística. Mesmo levando em consideração o valor máximo permitido e controlado por radar de $90 \mathrm{~km} \mathrm{~h}^{-1}$, a velocidade média dos veículos estimada dentro do túnel não ultrapassa os $70 \mathrm{~km} \mathrm{~h}^{-1}$. A grande quantidade de veículos, principalmente nas horas de pico, não permite o desenvolvimento de uma velocidade mais expressiva.

\section{Amostragem}

Foram escolhidos dois pontos de coleta dentro do túnel, o primeiro localizado a 500 metros da entrada pela zona sul (Humaitá) e o segundo distante 1500 metros dessa mesma entrada. Assim, a distância entre os dois pontos de monitoramento foi de 1000 metros. A Figura 2 apresenta a localização dos dois pontos de amostragem localizados dentro do túnel Rebouças.

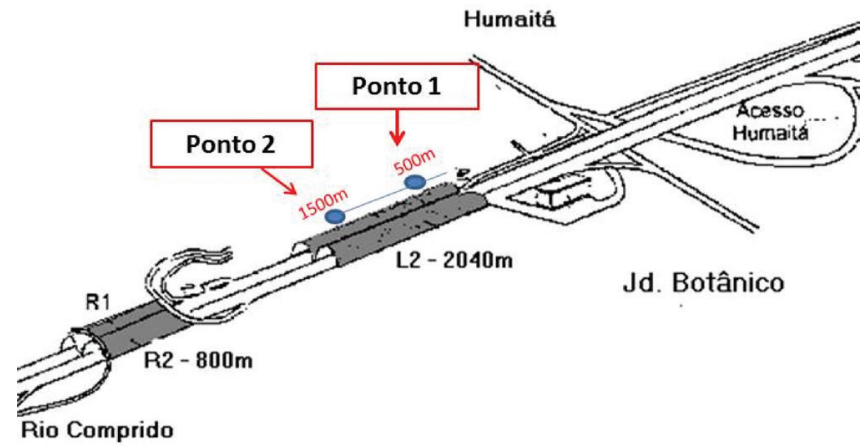

Figura 2. Esquema com a disposição das galerias e a localização dos pontos de coleta no túnel Rebouças

A escolha dos pontos de coleta é bastante crítica e apresenta grande variedade na bibliografia sobre o assunto. Alguns autores coletam a primeira amostra externamente ao túnel, perto da entrada, sendo a outra amostra coletada no interior do túnel. ${ }^{7-10}$ Em outros estudos, é escolhido um ponto de coleta no interior do túnel (entre 30 e $200 \mathrm{~m}$ da entrada) e outro ponto no interior, mais perto da saída. ${ }^{13-15}$ Como, por exemplo, no estudo realizado no túnel Shing Mun (Hong Kong), onde os autores coletaram a $686 \mathrm{~m}$ da entrada e a $350 \mathrm{~m}$ da saída. ${ }^{6}$ Neste trabalho optou-se pelas coletas nos pontos 1 e 2 (Figura 2), ambos localizados no interior do túnel. Esses pontos são locais utilizados como suporte pela administração do túnel e os únicos com a infraestrutura e segurança necessárias ao estudo. Foi decidido não realizar a coleta no exterior porque são locais localizados na encosta 
do maciço da Tijuca, em áreas pouco representativas, com grande ocorrência de emissões biogênicas e fortemente influenciadas por condições meteorológicas.

Para a determinação da taxa de emissão de compostos carbonílicos foram realizadas amostragens simultâneas, de aproximadamente 120 minutos de duração, em cada um dos pontos indicados na Figura 2. As coletas de compostos carbonílicos foram realizadas em oito campanhas, onde foram coletadas duas amostras por ponto. Assim, foram coletadas 16 amostras no ponto 1, mais próximo da entrada, e 16 no ponto 2, mais afastado desta mesma entrada. As campanhas foram realizadas nos dias 07 de fevereiro, 01 e 13 de março, 06 e 14 de dezembro de 2018, 10 de janeiro, 07 de fevereiro e 27 de março de 2019, sendo todos dias úteis. Durante as campanhas, a primeira coleta do dia era realizada, aproximadamente, entre 9:00 e 11:00 horas e a segunda entre 11:00 e 13:00 horas. Na Tabela 1S (Material Suplementar) são apresentados os dias e horários das campanhas realizadas.

Para as coletas foram utilizadas bombas de baixo volume modelo KNF NMP 850 operadas a bateria e calibradas com o calibrador DryCal, modelo DC-lite 717-04. Foram empregados cartuchos de $150 \mathrm{mg} \mathrm{SiO}{ }_{2}-\mathrm{C}_{18}$ (Sigma LpDNPH S10) impregnados com solução ácida de 2,4-dinitrofenilhidrazina (DNPH), que reage seletivamente com as carbonilas formando os respectivos derivados carbonilados de hidrazona.

Do total de oito campanhas realizadas, em cinco também foram monitorados $\mathrm{CO}, \mathrm{CO}_{2}$ e a temperatura, todos de forma contínua e com a utilização do analisador marca Instrutemp, modelo ITMCO2 - 600. Operando com a tecnologia de infravermelho não dispersivo (Non-Dispersive Infrared-NDIR), o equipamento processa medidas a cada minuto e os valores foram integrados para o mesmo tempo de coleta dos compostos carbonílicos.

\section{Análises químicas}

A coleta e determinação dos compostos carbonílicos foram baseadas no método U.S. EPA TO-11A. ${ }^{16,17}$ Os compostos foram eluídos dos cartuchos com acetonitrila (Merck, grau HPLC, teor mínimo de $99,9 \%$ ) e avolumados a $5 \mathrm{~mL}$. Os compostos carbonílicos foram analisados por cromatografia líquida de alta eficiência com um equipamento modelo Agilent Technologies 1100 Series, composto de bomba binária (G1379A), de autoamostrador (G1313A), de degaseificador (G1379A) e de um detector de UV-DAD, código G1315B $(\lambda=360 \mathrm{~nm})$. O volume de injeção foi padronizado em $10 \mu \mathrm{L}$ e o gradiente da fase móvel foi variável de 35\% de água ultrapura e $65 \%$ de acetonitrila (até os 9 minutos de corrida), passando para $100 \%$ de acetonitrila após os 9 minutos. A coluna utilizada na separação dos compostos foi uma Zorbax Eclipse XDB $(4,6 \mathrm{~mm} \times 15 \mathrm{~mm} \times 5 \mu \mathrm{m})$. O fluxo da bomba foi de $1,2 \mathrm{~mL} \mathrm{~min}^{-1}$ com 13 minutos de corrida e a temperatura do termostato foi ajustada em $30{ }^{\circ} \mathrm{C}$. Os padrões utilizados na análise foram preparados através da diluição da mistura Supelco (CARB Carbonyl-DNPH Mix 1) em acetonitrila. Foram geradas curvas com cinco níveis de concentração para todos os 13 compostos carbonílicos presentes no padrão. A integração dos picos foi realizada com o software ChemStation, desenvolvido pela Agilent Technologies. Os compostos e seus respectivos coeficientes de determinação foram: formaldeído $(0,9982)$, acetaldeído $(0,9983)$, acroleína $(0,9977)$, acetona $(0,9983)$, propionaldeído $(0,9999)$, crotonaldeído $(0,9975)$, metacroleína $(0,9975)$, butiraldeído $(0,9977)$, 2-butanona $(0,9969)$, benzaldeído $(0,9942)$, valeraldeído $(0,9986)$, ciclohexanona $(0,9865)$ e p-tolualdeído $(0,9975)$. O limite de quantificação (LQ) foi de $0,83 \mathrm{mg} \mathrm{m}^{-3}$ para formaldeído, 1,0 $\mathrm{mg} \mathrm{m}^{-3}$ para ciclohexanona e $0,42 \mathrm{mg} \mathrm{m}^{-3}$ para os demais compostos.

\section{Fator de emissão veicular}

A metodologia para cálculo do fator de emissão utilizada neste estudo é baseada no cálculo da diferença de concentração dos compostos medidos em dois pontos localizados no interior de um túnel. Considera que não ocorrem reações químicas entre os compostos emitidos e que a turbulência relacionada ao movimento dos veículos torna a mistura dos compostos sempre homogênea, independente do ponto de coleta. Nesse estudo foram calculadas as taxas de emissão utilizando as metodologias de Pierson e a metodologia que leva em consideração o consumo de combustível. . $7,18-21^{2}$

Na metodologia de Pierson, o cálculo do fator de emissão é realizado utilizando a equação (1). ${ }^{18,19}$

$$
E F=\frac{(\text { Cout }- \text { Cin }) A U t}{N L}
$$

em que: $\mathrm{EF}=$ Fator emissão veicular; Cout e Cin = representam as concentrações em massa de poluentes específicos nos dois pontos monitorados, em $\mathrm{mg} \mathrm{m}^{-3} ; \mathrm{A}=$ área da secção transversal do túnel, em $\mathrm{m}^{2} ; \mathrm{U}=$ velocidade do vento, $\mathrm{em} \mathrm{m} \mathrm{s}^{-1} ; \mathrm{t}=$ tempo de amostragem, em $\mathrm{s} ; \mathrm{N}=$ número de veículos; $\mathrm{L}=$ a distância entre os dois pontos monitorados, em $\mathrm{m}$.

Depois de processado na equação, o valor do fator de emissão foi expresso em $\mathrm{g} \mathrm{km}^{-1}$.

O cálculo do fator de emissão veicular a partir do consumo de combustível, é fundamentado na quantidade de poluente emitido por massa de combustível queimado, ou seja, considera que a concentração de um determinado composto de interesse será proporcional à massa de combustível queimado (expressa em concentração de $\mathrm{CO}$ e $\mathrm{CO}_{2}$ ), pela frota circulante. $\mathrm{O}$ cálculo do fator de emissão baseado no consumo de combustível é processado através da equação (2):

$$
E F=\frac{\Delta[\text { carbonila }]}{\Delta\left[\mathrm{CO}_{2}\right]+\Delta[\mathrm{CO}]} \times w c
$$

em que: EF é o fator de emissão; $\Delta$ [carbonila] é a diferença de concentração do composto carbonílico de interesse nos dois pontos monitorados; $\Delta\left[\mathrm{CO}_{2}\right]$ e $\Delta[\mathrm{CO}]$ é a diferença de concentração de $\mathrm{CO}_{2}$ e $\mathrm{CO}$ nos dois pontos monitorados; $\mathrm{w}_{\mathrm{c}}$ é a fração de carbono no combustível (0,87 para o diesel e 0,85 para gasolina). ${ }^{10,20,22}$

Por conta da composição da frota circulante no túnel Rebouças (94\% de veículos leves), a fração de veículos pesados foi desconsiderada. Porém, o valor de $\mathrm{w}_{\mathrm{c}}$ não necessariamente será 0,85 porque parte dos veículos utilizam etanol hidratado ou GNV. Como será discutido mais adiante, no Rio de Janeiro o consumo de etanol é relativamente menor que em outros lugares do país, podendo ser estimado em aproximadamente $20 \%$. $^{23}$ Assim, o valor de $\mathrm{w}_{\mathrm{c}}$ seria de aproximadamente 0,78 . Por outro lado, a frota que circula no Rio de Janeiro apresenta uma característica única, se comparada com o resto do país, é relativamente abundante de veículos que rodam no GNV, especialmente táxis e veículos de aplicativos. O GNV é constituído por aproximadamente $87 \%$ de metano e, dessa forma, tem um teor de carbono maior que o etanol e um pouco inferior à gasolina comercial. ${ }^{24,25}$ Neste trabalho foi utilizado o valor de 0,85 como uma aproximação, mas as implicações de valores menores serão discutidas.

\section{RESULTADOS E DISCUSSÃO}

Nos pontos 1 e 2 foram medidas temperaturas médias, para todos os dias de coleta, de $32,51 \pm 0,96{ }^{\circ} \mathrm{C}$ e $33,88 \pm 1,00{ }^{\circ} \mathrm{C}$ respectivamente. Esses valores são importantes na caracterização do túnel como 
um local relativamente blindado das alterações meteorológicas que ocorrem em ambientes abertos. A velocidade do vento, medida pelo anemômetro portátil modelo Thal-300, apresentou velocidade média de $20 \mathrm{~km} \mathrm{~h}^{-1}$ na direção do fluxo veicular.

$\mathrm{O} \mathrm{CO}$ e $\mathrm{o} \mathrm{CO}_{2}$ foram medidos de forma direta e contínua com dois monitores portáteis, um instalado no primeiro ponto de amostragem e outro no segundo ponto. Os valores foram obtidos a cada minuto e foi calculado um valor médio para o período de cada coleta. As concentrações médias para $\mathrm{CO}$ no primeiro ponto de amostragem, a $500 \mathrm{~m}$ da entrada do túnel, apresentaram valores entre 4,3 $\pm 2,5$ ppm e 7,6 $\pm 2,0$ ppm e para o segundo ponto, o intervalo foi de 13,3 \pm 4,6 até 29,9 \pm 4,7 ppm. Em relação ao $\mathrm{CO}_{2}$ os valores das concentrações médias para o primeiro ponto se encontraram entre $632,9 \pm 21,8$ ppm e $721,2 \pm 43,8$ ppm e no intervalo de $880,9 \pm 54,8 \mathrm{ppm}$ a $1091,3 \pm 92,7 \mathrm{ppm}$ para o segundo ponto de amostragem. A Figura 3 apresenta o resumo em boxplot das concentrações medidas para $\mathrm{CO}$ e $\mathrm{CO}_{2}$ nos pontos 1 e 2 .

\section{Concentrações CO}

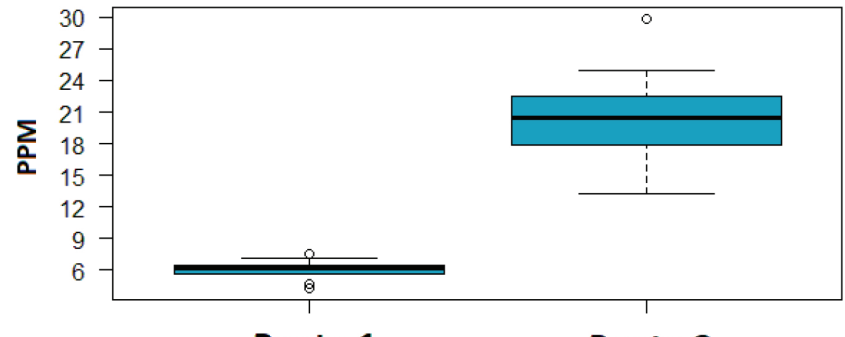

Ponto 1 Ponto 2

Concentrações $\mathrm{CO}_{2}$

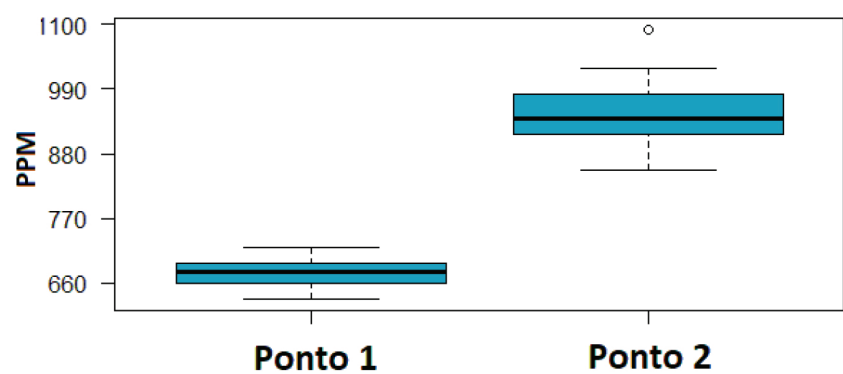

Figura 3. Concentrações de $\mathrm{CO}$ e $\mathrm{CO}_{2}$ determinadas no primeiro e no segundo pontos de monitoramento dentro túnel Rebouças. Os valores correspondem às médias para cada período de coleta de 120 minutos, em unidades de ppm

Em ambos pontos de coleta foram identificados os seguintes compostos carbonílicos: formaldeído, acetaldeído, acetona, propionaldeído e benzaldeído. Os outros compostos se encontraram com concentrações menores que o LQ. O formaldeído e acetaldeído foram os dois compostos mais abundantes. O formaldeído apresentou concentração média de $15,9 \pm 7,9 \mu \mathrm{g} \mathrm{m}^{-3}$ no primeiro ponto de amostragem e $26,9 \pm 8,5 \mu \mathrm{g} \mathrm{m}^{-3}$ no segundo ponto. Em relação ao acetaldeído, a média das concentrações foi de $22,0 \pm 8,5 \mu \mathrm{g} \mathrm{m}^{-3} \mathrm{e}$ $42,4 \pm 13,1 \mu \mathrm{g} \mathrm{m}^{-3}$ para o primeiro ponto e para o segundo ponto de amostragem, respectivamente. Esses valores indicam que o formaldeído e o acetaldeído representam aproximadamente $73 \%$ de todos os compostos carbonílicos identificados para o primeiro ponto e $80 \%$ para o segundo ponto de amostragem. Na Figura 4 são apresentadas, na forma de boxplot, as concentrações dos cinco compostos carbonílicos identificados.

Da mesma forma que ocorreu com o $\mathrm{CO}$ e o $\mathrm{CO}_{2}$, para os compostos carbonílicos também foram observadas concentrações maiores no ponto 2, se comparadas com as do ponto 1. Esse é o perfil
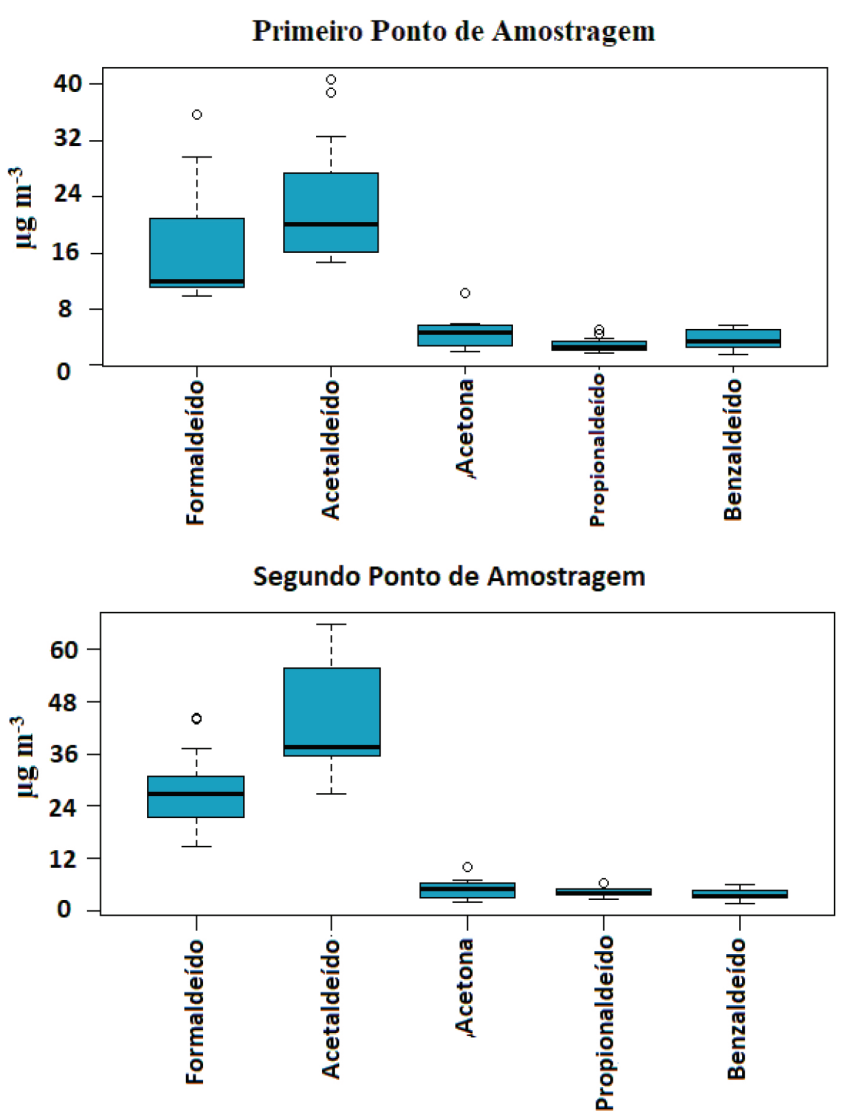

Figura 4. Concentrações dos compostos carbonílicos (em $\mu \mathrm{g} \mathrm{m}^{-3}$ ), determinadas no primeiro e no segundo pontos de monitoramento dentro túnel Rebouças. Foram coletadas 16 amostras em cada ponto

esperado também pelo princípio de acumulação, porque o ponto 2 de amostragem está mais distante da entrada do túnel que o ponto $1 . \mathrm{Na}$ Tabela 1 são apresentadas as relações percentuais de concentrações entre os dois pontos estudados.

Tabela 1. Relação percentual das concentrações medidas nos dois pontos de amostragem

\begin{tabular}{lc}
\hline Composto & $\begin{array}{c}\text { Relação percentual entre as } \\
\text { concentraçôe } \\
\text { Ponto2 / Ponto1 }\end{array}$ \\
\hline $\mathrm{CO}$ & $342 \%$ \\
$\mathrm{CO}_{2}$ & $140 \%$ \\
Formaldeído & $171 \%$ \\
Acetaldeído & $180 \%$ \\
Acetona & $111 \%$ \\
Propionaldeído & $154 \%$ \\
Benzaldeído & $110 \%$ \\
\hline
\end{tabular}

As maiores relações percentuais foram observadas para o $\mathrm{CO}$ (342\%), acetaldeído (180\%) e formaldeído (171\%).

Dentro do túnel, para os locais de coleta, a contribuição de reações fotoquímicas ou de outras fontes de emissão é desprezível, de forma que os compostos determinados são provavelmente oriundos apenas das emissões veiculares. A Figura 5 apresenta as relações do $\mathrm{CO}$ com o formaldeído e acetaldeído para as cinco campanhas nas quais foram medidos simultaneamente $\mathrm{CO}, \mathrm{CO}_{2}$ e compostos carbonílicos, em dois horários para cada campanha, conforme detalhado anteriormente. 

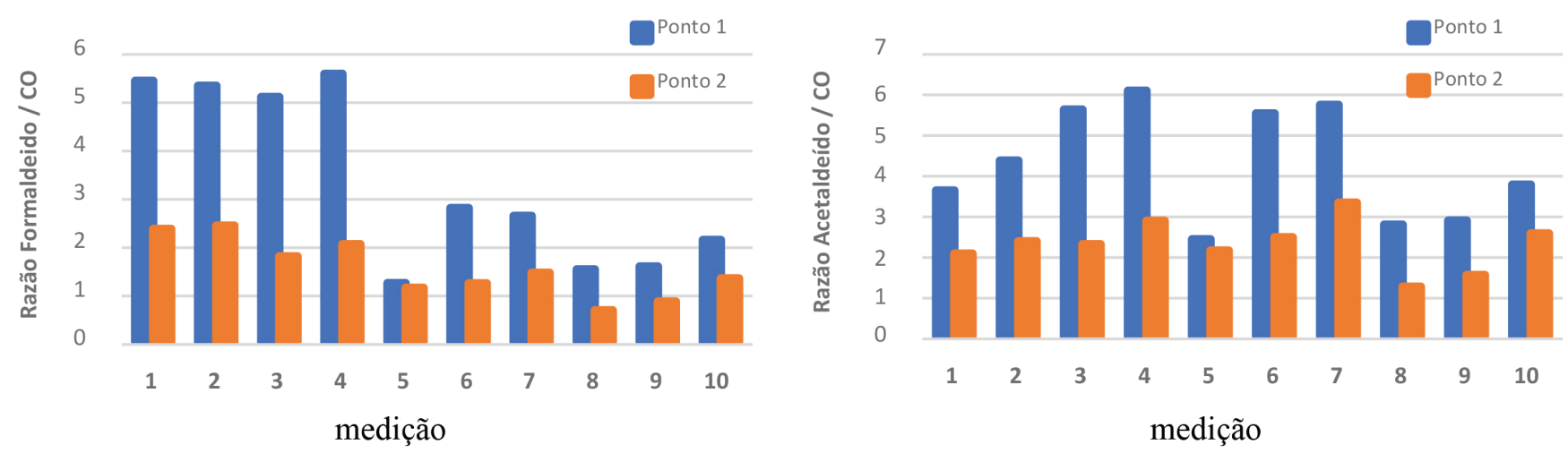

Figura 5. Razões entre as concentrações [formaldeído/[CO] e [acetaldeído]/[CO] calculadas para os dois pontos de coleta e os cinco dias em que foram determinados todos os compostos (duas determinações por dia)

A variabilidade das relações obtidas indica a possibilidade de mudanças nos fatores de emissão entre os diferentes dias de amostragem devido a fatores não determinados neste trabalho, como, por exemplo, velocidade média dos veículos e alterações no trânsito nos locais de acesso ao túnel, além de incertezas nas determinações experimentais.

\section{Taxas de emissão}

As taxas de emissão foram calculadas pela metodologia Pierson (equação 1) e pela de consumo de combustível (equação 2). Para aplicação da equação correspondente ao método de Pierson, foram necessários dados da frota circulante, das características físicas do túnel Rebouças (área da seção reta e distância entre os pontos monitorados), das concentrações dos compostos monitorados e da velocidade do vento medida no interior do túnel. Para a metodologia de consumo de combustível são necessárias as concentrações dos compostos monitorados, de $\mathrm{CO}$ e $\mathrm{CO}_{2}$, além do fator $\mathrm{w}_{\mathrm{c}}$ (equação 2).

Como já mencionado, foram realizadas oito campanhas com duas amostragens por campanha, totalizando trinta e duas amostras, dezesseis por ponto de coleta. Os dados referentes as características físicas do túnel foram apresentadas na parte experimental: área de seção reta de $81 \mathrm{~m}^{2}$ e distância entre os pontos de $1000 \mathrm{~m}$. A velocidade média do vento foi medida para cada dia de coleta e apresentou valores médios de $20 \mathrm{~km} \mathrm{~h}^{-1}$. A quantidade de veículos foi disponibilizada pela Prefeitura do Rio de Janeiro e para os dias das campanhas apresentou um valor médio de $5304 \pm 305$ veículos $\mathrm{h}^{-1}$, sendo que para cada horário foi utilizado o valor correspondente ao mesmo. A Tabela 2 apresenta os valores das taxas de emissão calculadas para os compostos carbonílicos pela metodologia de Pierson para as companhas de monitoramento realizadas no túnel Rebouças. Os valores das taxas de emissão estão expressos em $\mathrm{mg} \mathrm{km}^{-1}$.

A taxa de emissão média total para os compostos carbonílicos foi de $23,7 \pm 10,0 \mathrm{mg} \mathrm{km}^{-1}$. O acetaldeído contribuiu com $13,8 \pm 5,7 \mathrm{mg} \mathrm{km}^{-1}$, ou seja, $58 \%$ do total, o formaldeído foi o segundo composto mais abundante, representando $31,49 \%$ do total calculado.
Esse perfil é característico dos veículos abastecidos com gasolina ( $27 \%$ de etanol) e com etanol hidratado. ${ }^{26}$

As taxas de emissão calculadas pelo consumo de combustível, são expressas em unidade de massa de composto emitido por massa de combustível queimado. Dentro desta premissa, as medições de CO e $\mathrm{CO}_{2}$ se tornam indispensáveis e as concentrações apresentadas na Figura 3 foram utilizadas no denominador da equação 2 .

Para efeito de comparação das duas metodologias, foram estimados os valores em unidades de $\mathrm{mg} \mathrm{km}^{-1}$, a partir da densidade do combustível e o consumo médio dos veículos. Considerando que, a maioria dos veículos utiliza gasolina como combustível, foram utilizados os valores para esse combustível, sendo: densidade de $740 \mathrm{~g} \mathrm{~L}^{-1}$ e consumo médio de um veículo leve de $8,3 \mathrm{~km} \mathrm{~L}^{-1}{ }^{22}$ Dessa forma, os valores estimados para as taxas de emissão neste estudo, foram de $6,3 \pm 2,1,11,8 \pm 3,9,0,3 \pm 0,2$ e $0,2 \pm 1,0 \mathrm{mg} \mathrm{km}^{-1}$ para formaldeído, acetaldeído, acetona e benzaldeído, respectivamente.

Ao comparar os resultados obtidos pelos dois métodos, a diferença entre os valores médios para formaldeído e acetaldeído foi menor que $20 \%$. Para acetona e benzaldeído a diferença é muito maior, os valores obtidos pelo método de Pierson são 1,4 e 3,6 vezes maiores, respectivamente, provavelmente devido aos erros nas determinações desses compostos.

Para cada uma das metodologias foram realizadas uma série de aproximações e considerações que influenciaram os resultados obtidos. No método de Pierson, o principal erro é provavelmente a incerteza na contagem veicular, já que não existe uma contagem para cada dia específico no qual foram realizadas as determinações. Além da variação média relativa ao horário, existem outras variações difíceis de controlar, como por exemplo, engarrafamentos ou acidentes nas vias próximas de acesso ao túnel, que de certa forma, alteram o fluxo veicular. No caso do método de consumo de combustível, as maiores incertezas são, provavelmente, o fator $\mathrm{w}_{\mathrm{c}}$ (equação 2) e o consumo médio de combustível por veículo. $\mathrm{O}$ primeiro depende do combustível utilizado e, para o túnel Rebuças, não existem dados sobre o abastecimento dos veículos (etanol hidratado, gás natural veicular, gasolina ou diesel) ou até mesmo sobre a

Tabela 2. Valores calculados para as taxas de emissão $\left(\mathrm{mg} \mathrm{km}^{-1}\right)$ pela metodologia Pierson para as amostras de compostos carbonílicos coletados $(\mathrm{N}=16)$

\begin{tabular}{lcccccccccccccccccc}
\hline Composto & \multicolumn{11}{c}{ Medições } & \multicolumn{11}{c}{ Valor médio } \\
\hline Formaldeído & 8,50 & 12,80 & 6,30 & 8,78 & 4,03 & 8,97 & 4,61 & 8,71 & 9,42 & 5,66 & 9,27 & 7,40 & 6,51 & 5,25 & 2,93 & 10,35 & $7,5 \pm 2,6$ \\
Acetaldeído & 12,41 & 29,58 & 11,5 & 14,9 & 8,68 & 12,08 & 6,66 & 11,09 & 15,33 & 15,07 & 16,88 & 14,96 & 16,19 & 9,93 & 5,15 & 20,78 & $13,8 \pm 5,7$ \\
Acetona & 1,13 & 0,14 & 0,42 & 0,9 & 0,11 & 0,2 & nd & nd & nd & nd & 0,51 & nd & nd & 0,28 & 0,17 & 0,25 & $0,4 \pm 0,4$ \\
Propionaldeído & 1,81 & 2,24 & 0,82 & 1,41 & 0,75 & 1,14 & 0,92 & 0,66 & 0,78 & 1,21 & 1,20 & 1,05 & 0,98 & 0,98 & 0,54 & 1,45 & $1,1 \pm 0,5$ \\
Benzaldeído & 1,15 & 0,23 & nd & 0,6 & 0,78 & 0,04 & nd & 0,80 & 0,03 & 0,02 & 2,11 & 0,61 & 2,87 & 0,57 & 0,89 & 1,37 & $0,9 \pm 0,8$ \\
\hline
\end{tabular}

Nota. N: número de amostras; nd: não determinado. 
porcentagem de veículos flex-fuel que utilizam etanol hidratado. Em geral, pela localização geográfica do túnel, pode ser inferido que a frota circulante é composta por veículos relativamente novos e que, dessa forma, apresenta grande contribuição de veículos flex-fuel. Diferentemente de outros estados da federação, no Rio de Janeiro, os preços relativos do etanol hidratado e da gasolina favorecem ao abastecimento com gasolina. Conforme dados publicados pela Agência Nacional do Petróleo, no Rio de Janeiro, a comercialização de gasolina é 5,3 vezes maior que a de etanol hidratado, enquanto que em São Paulo essa relação é de $1,4 .{ }^{23}$ Outro fator de incerteza é o número de veículos que abastecem com GNV, que no Rio de Janeiro somam quase um milhão. ${ }^{25}$

Para estimar o erro introduzido com o coeficiente $c_{w}$, os valores de fatores de emissão foram recalculados utilizando o valor estimado para uma frota que utiliza $20 \%$ etanol hidratado e $80 \%$ gasolina, resultando em valores aproximadamente $10 \%$ menores. Essa diferença é muito menor que o desvio padrão das determinações.

O consumo médio de combustível é também uma fonte de incerteza. Neste trabalho foi utilizado o valor estimado por da Silva et al. (8,3 $\left.\mathrm{km} \mathrm{L}^{-1}\right) .{ }^{22}$ Outros dados da literatura informam valores entre 8 e $10 \mathrm{~km}$ $\mathrm{L}^{-1}$ para veículos leves movidos a etanol e gasolina, respectivamente, e $12 \mathrm{~km} \mathrm{~m}^{-3}$ para veículos que usam GNV. ${ }^{23}$ Assim, o valor pode estar subestimado. Considerando um valor de $10 \mathrm{~km} \mathrm{~L}^{-1}$, os fatores de emissão (em mg km${ }^{-1}$ ) seriam aproximadamente $20 \%$ menores.

Na Tabela 3 é apresentado um comparativo dos resultados deste estudo com outros trabalhos realizados no Brasil e também no exterior. Para comparação dos resultados, devem ser levados em consideração diversos fatores, tais como: combustível abastecido e características das frotas circulantes, que no Brasil também têm mudado consideravelmente nos últimos anos, como consequência da legislação que impôs limitações nos fatores de emissão.

Os valores calculados, neste estudo, para as taxas de emissão de acetaldeído são aproximadamente 1,8 vezes maiores que os valores obtidos para formaldeído. Trabalhos realizados em outros países mostram, em geral, o inverso. Essas diferenças podem ser atribuídas a diversos fatores, tais como mudanças no uso de combustíveis e diferenças tecnológicas nas frotas circulantes, principalmente em relação aos dispositivos de controle ambiental, devido à distância temporal entre os estudos e as características de consumo de energia de cada país. É notório que a frota que circula no túnel Rebouças, em sua maioria, já incorpora as recentes e mais eficientes tecnologias de controle das emissões, e esse fator pode ter sido de suma importância para a determinação dos valores encontrados. Além disso, e como já discutido, os veículos que circulam no túnel utilizam majoritariamente etanol e gasolina C (gasolina com $27 \%$ de etanol anidro) como combustível, para os quais as emissões de acetaldeído são maiores conforme dados obtidos em testes de homologação de veículos flex-fuel, ensaios utilizando dinamômetro de chassis e dados divulgados no ultimo inventário de emissões veiculares da CETESB. ${ }^{27,28}$

Em relação às taxas de emissão calculadas pela metodologia de consumo de combustível, no estudo realizado em São Paulo em 2011, para uma frota predominantemente de veículos leves, foram determinados os valores $5,7 \pm 1,7$ e 7,4 $\pm 2,7 \mathrm{mg} \mathrm{km}^{-1}$, para formaldeído e acetaldeído, respectivamente..$^{10}$ Os valores obtidos neste estudo, $6,3 \pm 2,1$ para formaldeído e $11,8 \pm 3,9 \mathrm{mg} \mathrm{km}^{-1}$ para acetaldeído, são ligeiramente superiores, mas estão em acordo quando considerados os desvios padrão dos resultados. Além da diferença entre as frotas circulantes em ambas as cidades, tanto quanto à idade como ao combustível utilizado, fatores associados à metodologia empregada na coleta podem ter sido determinantes para essa característica. Considerando o tipo de combustível, o uso de etanol hidratado em São Paulo é comparativamente maior, ${ }^{23}$ enquanto Rio de Janeiro possui a maior frota de veículos adaptados para GNV do país. ${ }^{24}$ Considerando essas características, seria esperado que a relação acetaldeído/formaldeído fosse maior na cidade de São Paulo que na do Rio de Janeiro. Além disso, outros fatores devem ser considerados, como, por exemplo, a localização dos pontos de coleta. Enquanto neste estudo os dois pontos de coleta se encontravam dentro do túnel, no estudo realizado em São Paulo um dos pontos era exterior ao túnel.

\section{Taxas de emissão}

Considerando a reatividade dos compostos carbonílicos e o potencial para formação de espécies secundárias, em especial o ozônio, foi avaliada a reatividade dos compostos medidos. Neste trabalho foi usada a escala de reatividade MIR (Maximum Incremental Reactivity) elaborada por Carter e colaboradores, para condições tipicamente urbanas e endossada pelo órgão ambiental dos Estados Unidos US EPA e pela CARB (California Air Resources Board), órgão ambiental da Califórnia. ${ }^{33,34}$

Definida como grama de ozônio produzido por grama de composto individual, a escala MIR é adimensional e seu valor representa o

Tabela 3. Comparação das taxas de emissão de compostos carbonílicos calculadas em este estudo com os valores determinados em outros estudos. Os valores estão em unidades de $\mathrm{mg} \mathrm{km}^{-1}$

\begin{tabular}{|c|c|c|c|c|c|c|c|}
\hline Local & Ano & Formaldeído & Acetaldeído & Acetona & Benzaldeído & Observações & Referência \\
\hline \multicolumn{8}{|c|}{ Metodologia Pierson } \\
\hline Rio de Janeiro, Brasil & $2018 / 2019$ & $7,5 \pm 2,6$ & $13,80 \pm 5,7$ & $0,4 \pm 0,4$ & $0,9 \pm 0,8$ & $\begin{array}{l}\text { Túnel Rebouças } \\
\text { (95\% veículos } \\
\text { leves) }\end{array}$ & Este estudo \\
\hline Estocolmo, Suécia & 1998/1999 & $4,9 \pm 4,6$ & $1,4 \pm 1,8$ & $1,5 \pm 1,8$ & $1,8 \pm 1,3$ & & 29 \\
\hline Zurique, Suiça & 1998 & $11,0 \pm 9$ & $2,3 \pm 1,2$ & $1,1 \pm 1,9$ & & & 30 \\
\hline Pensilvania, EUA & 1999 & 5,41 & 2,19 & 1,7 & 0,091 & & 31 \\
\hline Pensilvania, EUA & 1992 & 3,9 & nd & nd & nd & & 32 \\
\hline Hong Kong, China & 2007 & $18,8 \pm 7,5$ & $5,5 \pm 2,2$ & nd & nd & & 2 \\
\hline \multicolumn{8}{|c|}{ Metodologia por Consumo de Combustível } \\
\hline Rio de Janeiro, Brasil & $2018 / 2019$ & $6,3 \pm 2,1$ & $11,8 \pm 3,9$ & $0,3 \pm 0,2$ & $0,2 \pm 1,0$ & & Este estudo \\
\hline São Paulo, Brasil & 2006 & $48,40 \pm 35,1$ & $45,7 \pm 29,1$ & $9,3 \pm 4,4$ & nd & & 7 \\
\hline São Paulo, Brasil & 2011 & $5,7 \pm 1,7$ & $7,4 \pm 2,7$ & nd & nd & & 10 \\
\hline
\end{tabular}

Nota. nd: não determinado. 
maior rendimento para a formação de ozônio em relação a esse composto analisado. Levando em consideração essa premissa e baseado em estudos experimentais realizados em câmaras reacionais ( $\mathrm{smog}$ chambers), Carter tabelou centenas de compostos com base na sua reatividade. ${ }^{34}$ Essa tabela serve como ferramenta para comparação entre os diversos compostos individuais ou misturas de compostos.

O potencial para formação de ozônio (PFO) dos diferentes compostos foi calculado utilizando a equação 3 :

$$
\mathrm{PFO}_{\mathrm{i}}=\mathrm{MIR}_{\mathrm{i}} \times \text { concentração }_{i}
$$

em que: $\mathrm{PFO}_{\mathrm{i}}$ é o potencial formador de ozônio da espécie $\mathrm{i} ; \mathrm{MIR}_{\mathrm{i}}$ é o coeficiente MIR da espécie i (adimensional); Concentração $\mathrm{o}_{\mathrm{i}}$ a taxa de emissão da espécie i $\left(\mathrm{mg} \mathrm{km}^{-1}\right)$.

Na Tabela 4 são apresentados os valores de MIR, ${ }^{34}$ e o PFO calculado para os compostos determinados neste trabalho, usando a metodologia de Pierson para o cálculo das taxas de emissão.

Tabela 4. Valores dos coeficientes MIR e potencial formador de ozônio (PFO) para os principais compostos carbonílicos determinados neste trabalho

\begin{tabular}{lcc}
\hline Composto & $\mathrm{MIR}^{34}$ & $\mathrm{PFO}$ do composto $\left(\mathrm{mg} \mathrm{km}^{-1}\right)$ \\
\hline Formaldeído & 9,46 & $70,7 \pm 24,6$ \\
Acetaldeído & 6,54 & $90,4 \pm 37,3$ \\
Acetona & 0,36 & $0,09 \pm 0,12$ \\
Propionaldeído & 7,08 & $7,9 \pm 3,1$ \\
\hline
\end{tabular}

Nas amostras analisadas e levando em consideração as taxas de emissão calculadas pela metodologia de Pierson, o acetaldeído (PFO de 90,4 $\pm 37,3 \mathrm{mg} \mathrm{km}^{-1}$ ) e o formaldeído (PFO de 70,7 $\pm 24,6 \mathrm{mg} \mathrm{km}^{-1}$ ) foram os compostos que mais contribuem para a formação de ozônio.

\section{CONCLUSÕES}

Neste trabalho foram avaliadas as taxas de emissão dos compostos carbonílicos através de medições no interior do túnel Rebouças. O método utilizado neste estudo para o cálculo das taxas de emissão leva em consideração o "mundo real" da frota circulante, sob as condições reais de dirigibilidade, manutenção e combustível abastecido, nessa área da cidade do Rio de Janeiro. Os fatores de emissão calculados para os dois principais compostos carbonílicos, formaldeído e acetaldeído, foram de 7,5 $\pm 2,6$ e 13,8 $\pm 5,7 \mathrm{mg} \mathrm{km}^{-1}$, respectivamente, utilizando o método de Pierson. Utilizando o método de consumo de combustível, os valores foram $6,3 \pm 2,1$ e $11,8 \pm 3,9 \mathrm{mg} \mathrm{km}^{-1}$ para formaldeído e acetaldeído, respectivamente. Considerando as aproximações realizadas, principalmente na contagem dos veículos, na estimativa do fator $\mathrm{w}_{\mathrm{c}}$ e do consumo de combustível, o acordo entre os valores é aceitável e indicam que ambos os métodos fornecem resultados compatíveis. Os resultados são, também, compatíveis com valores obtidos em São Paulo no túnel Jânio Quadros, em 2011, com predominância de veículos leves.

As emissões de acetaldeído foram estimadas em, aproximadamente, 1,8 vezes maiores que as de formaldeído, tanto pelo método de Pierson quanto no de consumo de combustível. Essa relação está de acordo com resultados obtidos em testes de emissão realizados em dinamômetro de chassis, em que relações acetaldeído/formaldeído foram medidas entre 4 e 6 para veículos abastecidos com etanol hidratado e entre 1 e 2 quando abastecidos com gasolina comercial.

A relação acetaldeído/formaldeído relativamente alta em comparação com os valores médios em outros lugares do mundo, podem ser atribuídas ao uso do etanol hidratado e de gasolina com o agregado de etanol anidro (gasolina C), especialmente por veículos flex-fuel que emitem em geral mais compostos carbonílicos que os veículos para gasolina. A comparação dos resultados obtidos neste trabalho com outros obtidos há mais de 10 anos mostra uma grande redução nas emissões atribuída aos avanços na tecnologia, principalmente as de controle ambiental. Porém, considerando que o material particulado e o ozônio são, em geral, os poluentes mais preocupantes nas cidades brasileiras e que os compostos carbonílicos tem um alto potencial formador de ozônio, novos esforços no sentido de diminuir ainda mais as emissões, principalmente de acetaldeído, se fazem necessários.

Novos estudos deverão ser realizados no futuro para determinar fatores de emissão em outras áreas da cidade do Rio de Janeiro, com outras características de frota veicular e uso de combustíveis.

\section{REFERÊNCIAS}

1. Anenberg, S. C.; Miller, J.; Minjares, R.; Du, L.; Henze, D. K.; Lacey, F.; Malley C. S.; Emberson, L.; Franco, V.; Klimont, Z.; Heyes, C.; Nature 2017, 7655, 467.

2. Ho, K. F.; Ho, S. S. H.; Chenga Y.; Lee, S. C.; Yu, J. Z.; Atmos. Environ. 2007, 41, 1747.

3. https://www.epa.gov/air-emissions-inventories/air-pollutant-emissionstrends-data, acessada em Março 2020.

4. https://publications.europa.eu/en/publication-detail/-/ publication/223e663b-1340-11e9-81b4-01aa75ed71a1, acessada em Março 2020.

5. https://cetesb.sp.gov.br/ar/wp-content/uploads/sites/28/2019/07/ Relatório-de-Qualidade-do-Ar-2018.pdf, acessada em Março 2020.

6. Cui, L.; Wang, X. L.; Ho, K. F.; Atmos. Environ. 2018, 177, 64.

7. Martins, L. D.; Andrade, M. F.; Freitas, E. D.; Pretto, A.; Gatti, L. V.; Albuquerque, A. L.; Tomaz, E.; Guardani, M. L.; Martins, M. H. R. B.; Junior, O. M. A.; Environ. Sci. Technol. 2006, 40, 6722.

8. Sánchez-Ccoyllo, O. R.; Ynoue, R. Y.; Martins, L. D.; Astolfo, R.; Miranda, R. M.; Freitas, E. D.; Borges, A. S.; Fornaro, A.; Freitas, H.; Moreira, A.; Andrade, M. F.; Environ. Monit. Assess. 2009, 149, 241.

9. Pérez-Martínez, P. J.; Miranda, R. M.; Nogueira, T.; Guardani, M. L.; Fornaro, A.; Ynoue, R.; Andrade, M. F.; Int. J. Environ. Sci. Technol. 2014, 11, 2155.

10. Nogueira, T.; Souza, K. F.; Fornaro, A.; Andrade, M. F.; Carvalho, L. R. F.; Atmos. Environ. 2015, 108, 88.

11. https://www.ibge.gov.br/cidades-e-estados/rj.html, acessada em Março 2020.

12. Machado, M. C. S.; Almeida, J. C. S.; Martins, E. M.; Arbilla, G.; Bull. Environ. Contam. Toxicol. 2007, 78, 304.

13. Zhang, Q.; Wu, L.; Fang, X.; Liu, M.; Zhang, J.; Shao, M.; Lu, S.; Mao, H.; Sci. Total Envion. 2018, 624, 878.

14. Huang, C.; Tao, S.; Lou, S.; Hu, Q.; Wang, H.; Wang, Q.; Li, L.; Wang, H.; Liu, J.; Quan, Y.; Zhou, L.; Atmos. Environ. 2017, 169, 193.

15. Stemmler, K.; Bugmann, S.; Buchmann, B.; Reimann, S.; Staehelin, J.; Atmos. Environ. 2005, 39, 1009.

16. https://www3.epa.gov/ttnamti1/files/ambient/airtox/to-11ar.pdf, acessada em Março 2020.

17. Custódio, D.; Guimarães, C. S.; Varandas, L.; Arbilla, G.; Chemosphere 2010, 79, 1064.

18. Pierson, W. R.; Gertler, A. W.; Robinson, N. F.; Sagebiel, J. C.; Zielinska, B.; Bishop, G. A.; Stedman, D. H.; Zweidinger, R. B.; Ray, W. D.; Atmos. Environ. 1996, 30, 2233.

19. Pierson, W. R.; Gertler, A. W.; Bradow, R. L.; J. Air Waste Manage Assoc. 1990, 40, 1495.

20. Mcgaughey, G. R.; Desai, N. R.; Allen, D. T.; Seila, R. L.; Lonneman, W. A.; Fraser, M. P.; Harley, R. A.; Pollack, A. K.; Ivy, J. M.; Price, J. H.; Atmos. Environ. 2004, 38, 3363. 
21. Alves, C. A., Gomes, J.; Nunes, T.; Duarte, M.; Calvo, A.; Custódio, D.; Pio, C.; Karanasiou, A.; Querol, X.; Atmos. Res. 2015, 153, 134.

22. Da Silva, D. B. N.; Martins, E. M.; Corrêa, S. M.; Environ. Monit. Assess. 2016, 188, 5 .

23. http://www.anp.gov.br/dados-estatisticos, acessada em Março 2020.

24. http://www.detran.rj.gov.br/_estatisticas.veiculos/index.asp, acessada em Março 2020.

25. http://www.br.com.br/pc/produtos-e-servicos/para-seu-veiculo/gasnatural-veicular, acessada em Março 2020.

26. Corrêa, S. M.; Arbilla, G.; Martins, E. M.; Quitério, S. L.; Guimarães, C. S.; Gatti, L. V.; Atmos. Environ. 2010, 44, 2302.

27. https://cetesb.sp.gov.br/escolasuperior/wp-content/uploads/ sites/30/2016/06/PAP47-1.pdf. acessada em Março 2020.

28. https://cetesb.sp.gov.br/veicular/wp-content/uploads/sites/6/2019/12/ Emissões-Veiculares-no-Estado-de-São-Paulo-Relatório-2018.pdf, acessada em Março 2020.
29. Kristensson, A.; Johanssonb, C.; Westerholme, R.; Swietlickia, E.; Gidhagenb, L.; Wideqvistb, U.; Vesely, V.; Atmos. Environ. 2004, 38, 657.

30. Staehelin, J.; Keller, C.; Stahel, W.; Schlapfer, K.; Wunderl, S.; Atmos. Environ. 1998, 32, 999

31. Grosjean, D.; Grosjean, E.; Gertler, A. W.; Environ. Sci. Technol. 2001, 35,45 .

32. Zielinska, B.; Sagebiel, J. C.; Harshfield, G.; Gertler, A. W.; Pierson, W. R.; Atmos. Environ. 1996, 30, 2269.

33. Carter, W.; Atmos. Environ. 2010, 40, 5324.

34. https://ww3.arb.ca.gov/regact/2009/mir2009/mir10.pdf, acessada em Março 2020. 